\title{
Introduction
}

\section{What our hopes and fears tell us about our values}

\section{Allen Alvarez, Espen Dyrnes Stabell \& May Thorseth}

The global community has overcome great challenges after more than a year of battling the COVID-19 pandemic. This first issue of Etikk i praksis - Nordic Journal of Applied Ethics for the year 2021 comes out as 2.18 billion doses of COVID-19 vaccines have been administered around the world (Holder 2021). Averaging these doses across the total world population yields an ideal distribution of 28 per 100 people vaccinated. However, the reality is that many populations in different countries have not received any of those doses yet, while people in other countries have the luxury to avoid certain vaccines because of concerns about adverse reactions. Achieving herd immunity and avoiding the emergence of vaccineresistant variants of COVID-19 require that vaccines are distributed more widely, if not equitably, among different populations around the world and not just in high income countries. Most ethical global frameworks for vaccine distribution highlight four values: “...helping the neediest, reducing health disparities, saving lives and keeping society functioning" (Jecker, et al. 2021). The dire global situation has pushed many societies to take social justice seriously because the risks of not doing so can seriously affect even those countries who can afford the cost of providing vaccines to all of their citizens.

Our hope for ending the global spread of COVID-19 points out how important it is to keep our communities safe from the harms of this terrible pandemic. That same hope also makes clear that global justice and equitable distribution of lifesaving resources, like vaccines, are not only important for their own sake but also because equitable distribution may be more effective in protecting us all. Indeed, delaying access to vaccines in other countries could result in the spread of new variants that can pose risks even to fully vaccinated populations, no matter the amount of vaccines that rich countries have.

Our fear of facing more years under pandemic infection control restrictions helps us recognize the importance of enjoying freedom of movement, the value of social interaction and having fewer restrictions in our lives as much as possible. These challenging times give everyone opportunity to think about what should matter most and how we can engage each other in thinking hard about our collective values. This engagement - using the methods and theories in applied ethics to enable well-reasoned decisions about what should matter most in times of crisis - is one of the important objectives of Etikk i Praksis - Nordic Journal of Applied Ethics. 
This open issue of the Nordic Journal of Applied Ethics consists of four papers that discuss topics covering fetal diagnostics ethics, value conflicts in the use of artificial intelligence, abortion and population ethics.

The first article in this issue by Nora Levold, Marit Svingen, \& Ingrid Bruholt is entitled Fosterdiagnostikk mellom medisin og etikk: Implementering av NIPT-testen $i$ et urolig politikkområde (Fetal diagnostics between medicine and ethics: Implementation of non-invasive prenatal testing in a turbulent policy area) and examines how the decision to implement non-invasive prenatal testing (NIPT) in the Norwegian Fetal Diagnostic System was reached through a professional policy process between 2012 and 2017. The authors present a careful convergence that took place between the traditionally opposing (and mutually exclusive) ways to understand and frame fetal diagnostics in Norway. They refer to those opposing approaches as a 'treatment frame' and a 'sorting frame'. This convergence was possible because the process was kept within the bureaucracies of the Norwegian Centre for Health Services Research, the Norwegian Directorate of Health, the Norwegian Biotechnology Advisory Board and the Ministry of Health and Care Services. These different agencies were willing to collaborate to include knowledge and values from both frames in their recommendations. The authors also present the fragility of this convergence, because fetal diagnostics policy remains controversial in Norwegian politics. They recount the collapse of the convergence during the three weeks of May 2020 when the Norwegian Progress Party suddenly entered a "biotechnology settlement" with the Labour Party and the Socialist Left Party after exiting the conservative Government coalition. The authors acknowledge the almost unsolvable dilemmas these framings both produce and represent.

The second article by Thomas Søbirk Petersen - "Ethical guidelines for the use of artificial intelligence and value conflict challenges" - critically examines the value conflicts that arise in ethical guidance of the use of artificial intelligence. Guidelines for ethical analysis of AI use are indeed useful, but their utility can be undermined by the conflicting values they aspire to enable. Petersen aims to show the need for distinguishing between three kinds of conflict that can exist for ethical guidelines and discusses different approaches to handling internal and external values conflicts. The author presents three strategies to resolve genuine value conflict: (1) accepting the existence of irresolvable conflict, (2) ranking (prioritization) of values, and (3) value monism. Of these three, the author defends the view that irresolvable conflicts should be accepted. While acknowledging the theoretical advantage of adopting the ranking view and value monism, real-life decisionmaking in AI guidance requires accepting irresolvable value conflicts to solve genuine conflicts among values in ethical guidelines in.

The third article by Silje Langseth Dahl, Rebekka Hylland Vaksdal, Mathias Barra, Espen Gamlund and Carl Tollef Solberg is an English translation of a previously published Norwegian article on abortion and multifetal pregnancy reduction. This translation moves the controversial discussion beyond the Norwegian public sphere to include a wider audience and invite broader reflection on the issue. Multifetal pregnancy reduction (MFPR) continues to be a subject of fierce debate in Norway. The intensity of this debate reached a high point when the Legislation Department delivered its interpretative statement, Section 2 Interpretation of the Abortion Act in 2016, in response to a request from the 
Ministry of Health (2014) that the Legislation Department consider whether the Abortion Act allows for MFPR of healthy fetuses in multiple pregnancies. The Legislation Department concluded that the current abortion legislation (as of 2016) allows for MFPR subject to the constraints that the law otherwise stipulates. The debate has not subsided and was further intensified during autumn 2018 in connection with the Norwegian Christian Democratic "crossroads" policy and signals from the Conservatives to consider removing section $2.3 \mathrm{c}$ and to prohibit MFPR. Many of the arguments in the MFPR debate appear similar to arguments put forward in the general abortion debate, and an analysis to ascertain what distinguishes MFPR from other abortions has yet to be conducted. The authors invite readers to examine whether there is a moral distinction between abortion and MFPR of healthy fetuses. They present typical arguments emerging in the debate in Norway and illustrate them with scholarly articles from the literature. After presenting the most important arguments against MFPR - the harm argument, the slippery-slope argument, the intention argument, the grief argument, the long-term psychological effects for the woman argument and the sorting argument - they concluded that these arguments did not succeed in demonstrating morally relevant differences between MFPR of healthy fetuses and other abortions. Hence, the authors maintain the view that there is no morally relevant difference between the two and that the same conditions for allowing MFPR should follow as for other abortions.

The fourth article by Mat Rozas examines a dilemma in reproductive and population ethics that can illuminate broader questions in value theory and normative ethics. Rozas reminds readers that most people have conflicting intuitions concerning whether the interests of non-existent but potential beings can outweigh the interests of existing beings. Those merely potential (non-existent) beings are expected to have overall net-good or overall net-bad lives. The author claims that the standard approach to this issue is not correct. Instead, Rozas suggests that we approach the issue through the distinction between Symmetrical and Asymmetrical Views about the relative importance of positive and negative value and the claim that Asymmetrical Views give the most intuitively satisfactory solution to the dilemma examined in the article. Rozas notes that most authors hold the standard interpretation of what explains our asymmetrical attitudes toward having the Happy Child and not having the Wretched Child, but he suggests the asymmetry between positive and negative value as an alternative account. Rozas argues that readers should consider negative value more important than positive value. While asymmetric views consider suffering as something negative, they need not consider happiness as something positive. Lives where suffering prevails are net negative, but asymmetric views need not consider lives where happiness prevails as net positive. When we compare (a) sacrificing one life and bringing another into existence with (b) not doing any of these two things, we may think that sacrificing life (a) is worse than not doing anything (b). Those who hold the so-called Personaffecting asymmetric views will claim that (a) is worse, while Impersonal asymmetric views will consider (a) and (b) equivalent. Rozas provides a different explanation for the asymmetric view regarding attitudes toward bringing happy children into existence and bringing wretched children into existence that is different from the more widely held person-affecting views. His theoretical examination of these intuitions can help sharpen our understanding of the 
implications of trade-offs we need to make in creating policies that affect populations, including those that affect future generations.

Finally, our book review for this issue by Alexander Myklebust explores ideas related to how Responsible Research and Innovation (RRI) can be practised and assessed in the future. RRI scholars will have to figure out whether they want to hold onto a science-oriented RRI or fully embrace the systems approach. Myklebust commends the way in which several of the authors of the reviewed volume have broadened the scope of RRI towards a genuinely systems-oriented approach. Myklebust considers approaches that are more in line with a linear method to be suitable for contexts where it is possible to envisage a more or less step-wise innovation trajectory that can be assessed either at an early stage or throughout the process of developing innovative technology. It might be true today that many, if not most, innovations are more or less systemic in nature. But in cases where innovation processes are driven by research and development, there will still be a need for methods that focus on stakeholder involvement and foresight geared towards tackling fundamental problems.

The editors of Etikk i praksis invite readers to continue reflecting on ways we can resolve the decision dilemmas we face in these challenging times. Identifying what should matter most in these decisions is a crucial step. Reflecting on choices that support the most reasonable solutions and the trade-off of values we make is another.

\section{References}

Holder, J. (2001). Tracking Coronavirus Vaccinations Around the World. The New York Times. Available at: https:/www.nytimes.com/interactive/2021/world/ covid-vaccinations-tracker.html Date accessed: June 8, 2021.

Jecker, N. S., Wightman, A. G., \& Diekema, D. S. (2021). Vaccine ethics: an ethical framework for global distribution of COVID-19 vaccines. Journal of Medical Ethics, 47(5), 308-317. http://dx.doi.org/10.1136/medethics-2020-107036 